\title{
Heterogeneous Catalysts in Pictet-Spengler-Type Reactions
}

\author{
Rodolfo Quevedo, ${ }^{1}$ Camilo Perdomo, ${ }^{2}$ and Sonia Moreno ${ }^{2}$ \\ ${ }^{1}$ Departamento de Química, Facultad de Ciencias, Universidad Nacional de Colombia, Sede Bogotá, 45-03 Carrera 30, \\ Bogotá 4-72, Colombia \\ ${ }^{2}$ Estado Solido y Catálisis Ambiental (ESCA), Departamento de Química, Facultad de Ciencias, Universidad Nacional de Colombia, \\ Sede Bogotá, 45-03 Carrera 30, Bogotá 4-72, Colombia \\ Correspondence should be addressed to Rodolfo Quevedo; arquevedop@unal.edu.co
}

Received 7 June 2012; Revised 25 July 2012; Accepted 8 August 2012

Academic Editor: Adriana Szeghalmi

Copyright ( 2013 Rodolfo Quevedo et al. This is an open access article distributed under the Creative Commons Attribution License, which permits unrestricted use, distribution, and reproduction in any medium, provided the original work is properly cited.

Several solid catalysts were evaluated as an alternative for 1,2,3,4-tetrahydroisoquinoline synthesis by means of the Pictet-Spengler reaction. The reaction catalysed by a mixed oxide ( $\mathrm{Mg}$ and $\mathrm{Al})$ led to the best yield and good regioselectivity; using an $\mathrm{Al}$-pillared bentonite led to good yields and total regioselectivity. The results revealed no direct relationship between catalyst acidity and yield.

\section{Introduction}

Tetrahydroisoquinolines are present in many natural or synthetic organic compounds; they have varied biological activity $[1-5]$. Such compounds are usually obtained by adding a $\beta$-phenylethylamine to a carbonyl compound to form an imine. Activating such imine by adding an acid promotes the formation of the respective tetrahydroisoquinoline by means of electrophilic aromatic substitution (known as the PictetSpengler reaction (Scheme 1) [6].

The Pictet-Spengler reaction (usually carried out in an aprotic solvent in the presence of an acid catalyst) occurs more easily when a phenylethylamine's aromatic ring is activated by electrodonor substituents on carbon 3 [6]; this does not happen when the phenylethylamine only has a hydroxyl on carbon $4[7,8]$. Regioselectivity depends on activating the phenylethylamine aromatic ring and the less hindered ortho position usually predominates for cyclisation. Such pattern improves when the reaction is carried out in protic solvents $[9,10]$.

Brǿnsted acids (i.e., acetic acid or trifluoroacetic acid) are usually used for promoting imine cyclisation formed by adding phenylethylamine to the carbonyl compound. Brǿnsted acids such as p-toluensulphonic acid [11], perfluoroctasulphonic acid [12], phosphate buffer [13], and Lewis acids, such as calcium complexes [14] and $\mathrm{Yb}(\mathrm{OTf})_{3}$ [15], have been used more recently in the search for better yields and greater regioselectivity.

On the other hand, solid acids or bases such as natural or modified clays, zeolites, and mixed oxides have been used for various processes regarding organic synthesis in the search for environmentally friendly, economic processes which can be applied at industrial level. $\mathrm{H}^{+}$-montmorillonites and zeolites have been particularly used for this reaction [16-18].

Different solids were evaluated as catalysts for the reaction between dopamine hydrobromide and aromatic aldehydes aimed at contributing towards the search for more efficient and environmentally friendly conditions and establishing the possible influence of catalyst acidity on the course of the Pictet-Spengler reaction.

\section{Experimental Section}

2.1. General Procedure for Solid-Catalysed Pictet-Spengler Type Reactions. The solid catalyst $(100 \mathrm{mg})$ was added to a solution of dopamine hydrobromide $(100 \mathrm{mg})$ and the respective aldehyde (stoichiometric) in methanol; the mixture was refluxed for $72 \mathrm{~h}$. The catalyst was filtered and washed with methanol. The solvent was then removed under reduced pressure, and the resulting solid was washed with $\mathrm{CHCl}_{3}$. The crude solid ${ }^{1} \mathrm{H}-\mathrm{NMR}$ spectrum was recorded in $\mathrm{CD}_{3} \mathrm{OD}[10]$. 


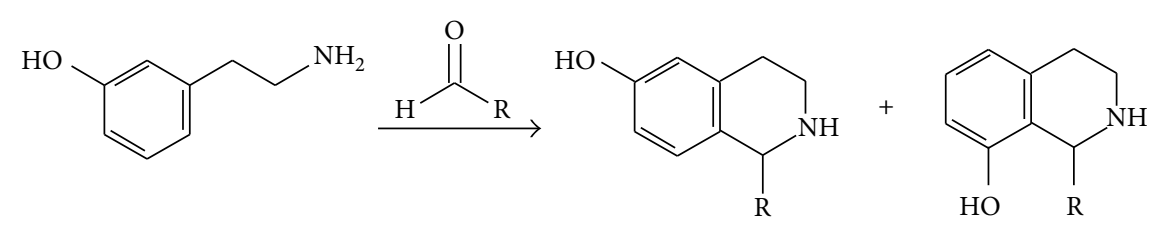

Scheme 1: Pictet-Spengler reaction.

Dopamine hydrobromide. ${ }^{1} \mathrm{H}-\mathrm{NMR}\left(\mathrm{CD}_{3} \mathrm{OD}, 400 \mathrm{MHz}\right): 2.83$ $(2 \mathrm{H}, \mathrm{d}, J=7.2 \mathrm{~Hz}), 3.13(2 \mathrm{H}, \mathrm{d}, J=7.2 \mathrm{~Hz}), 6.61(1 \mathrm{H}, \mathrm{dd}$, $J 1=7.2 \mathrm{~Hz}, J 2=2.0 \mathrm{~Hz}), 6.72(1 \mathrm{H}, \mathrm{d}, J=2 \mathrm{~Hz}), 6.76(1 \mathrm{H}, \mathrm{d}$, $J=8 \mathrm{~Hz}$ ).

6,7-Dihydroxy-1-(3-nitrophenyl)-1,2,3,4-tetrahydroisoquinoline Hydrobromide 3a. ${ }^{1} \mathrm{H}-\mathrm{NMR}\left(\mathrm{CD}_{3} \mathrm{OD}, 400 \mathrm{MHz}\right): 3.08$ $(1 \mathrm{H}, \mathrm{m}), 3.19(1 \mathrm{H}, \mathrm{m}), 3.51(2 \mathrm{H}, \mathrm{m}), 5.86(1 \mathrm{H}, \mathrm{s}), 6.21$ $(1 \mathrm{H}, \mathrm{s}), 6.76(1 \mathrm{H}, \mathrm{s}), 7.78(1 \mathrm{H}, \mathrm{t}, J=7.6 \mathrm{~Hz}), 7.84(1 \mathrm{H}, \mathrm{d}$, $J=7.4 \mathrm{~Hz}), 8.33(1 \mathrm{H}, \mathrm{s}), 8.37(1 \mathrm{H}, \mathrm{d}, 8.0 \mathrm{~Hz})$.

7,8-Dihydroxy-1-(3-nitrophenyl)-1,2,3,4-tetrahydroisoquinoline Hydrobromide 4a. ${ }^{1} \mathrm{H}-\mathrm{NMR}\left(\mathrm{CD}_{3} \mathrm{OD}, 400 \mathrm{MHz}\right): 3.04$ $(1 \mathrm{H}, \mathrm{m}), 3.23(1 \mathrm{H}, \mathrm{m}), 3.37(2 \mathrm{H}, \mathrm{m}), 6.05(1 \mathrm{H}, \mathrm{s}), 6.75(1 \mathrm{H}, \mathrm{d}$, $J=7.6 \mathrm{~Hz}), 6.91(1 \mathrm{H}, \mathrm{d}, J=8.0 \mathrm{~Hz}), 7.70(2 \mathrm{H}$, overlapped $)$, $8.22(1 \mathrm{H}, \mathrm{s}), 8.30(1 \mathrm{H}, \mathrm{d}, J=8 \mathrm{~Hz})[10]$.

6,7-Dihydroxy-1-(4-hydroxy-3-methoxyphenyl)-1,2,3,4-tetrahydroisoquinoline Hydrobromide $3 \mathbf{b} .{ }^{1} \mathrm{H}-\mathrm{NMR}\left(\mathrm{CD}_{3} \mathrm{OD}\right.$, $400 \mathrm{MHz}): 3.02(1 \mathrm{H}, \mathrm{m}), 3.17(1 \mathrm{H}, \mathrm{m}), 3.43(1 \mathrm{H}, \mathrm{m}), 3.50$ $(1 \mathrm{H}, \mathrm{m}), 3.86(3 \mathrm{H}, \mathrm{s}), 6.28(1 \mathrm{H}, \mathrm{s}), 6.70(1 \mathrm{H}, \mathrm{s}), 6.82(1 \mathrm{H}, \mathrm{d}$, $J=8.2 \mathrm{~Hz}), 6.88(1 \mathrm{H}, \mathrm{d}, J=8.0 \mathrm{~Hz}), 6.97(1 \mathrm{H}, \mathrm{s})$.

7,8-Dihydroxy-1-(4-hydroxy-3-methoxyphenyl)-1,2,3,4-tetrahydroisoquinoline Hydrobromide $4 \mathbf{b} .{ }^{1} \mathrm{H}-\mathrm{NMR}\left(\mathrm{CD}_{3} \mathrm{OD}\right.$, $400 \mathrm{MHz}): 2.99(1 \mathrm{H}, \mathrm{m}), 3.16(1 \mathrm{H}, \mathrm{m}), 3.46(1 \mathrm{H}, \mathrm{m}), 3.52$ $(1 \mathrm{H}, \mathrm{m}), 3.86(3 \mathrm{H}, \mathrm{s}), 5.30(1 \mathrm{H}, 1), 6.79(1 \mathrm{H}, \mathrm{d}, J=8.0 \mathrm{~Hz})$, $6.88(1 \mathrm{H}, \mathrm{d}, J=8.0 \mathrm{~Hz}), 6.97(1 \mathrm{H}, \mathrm{d}, J=8 \mathrm{~Hz}), 7.00(1 \mathrm{H}, \mathrm{d}$, $J=1.6 \mathrm{~Hz}), 7.45(1 \mathrm{H}, \mathrm{dd}, J 1=7.6 \mathrm{~Hz}, J 2=1.6 \mathrm{~Hz})$.

2.2. Dopamine Reaction with 3-Nitrobenzaldehyde. The solid catalyst $(100 \mathrm{mg})$ was added to a solution of dopamine $(100 \mathrm{mg})$ and 3-nitrobenzaldehyde (stoichiometric) in methanol; the mixture was refluxed for $12 \mathrm{~h}$. The catalyst was filtered and washed with methanol. The solution was then concentrated at reduced pressure and placed in an ice bath. The precipitate so formed was filtered and washed in cold methanol (giving 95\% yield).

6,7-Dihydroxy-1-(3-nitrophenyl)-1,2,3,4-tetrahydroisoquinoline. melting point not determined (product decomposed at a point below melting point), ${ }^{1} \mathrm{H}-\mathrm{NMR}\left(\mathrm{CD}_{3} \mathrm{OD}, 400 \mathrm{MHz}\right)$ : $2.98(1 \mathrm{H}, \mathrm{m}), 3.12(1 \mathrm{H}, \mathrm{m}), 3.41(2 \mathrm{H}, \mathrm{m}), 5.64(1 \mathrm{H}, \mathrm{s}), 6.18$ $(1 \mathrm{H}, \mathrm{s}), 6.72(1 \mathrm{H}, \mathrm{s}), 7.73(1 \mathrm{H}, \mathrm{t}, J=8.0 \mathrm{~Hz}), 7.78(1 \mathrm{H}, \mathrm{d}$, $J=7.6 \mathrm{~Hz}), 8.30(1 \mathrm{H}, \mathrm{s}), 8.33(1 \mathrm{H}, \mathrm{d}, 8.0 \mathrm{~Hz})[10]$.

\section{Results and Discussion}

The following aldehydes were studied. 3-nitrobenzaldehyde 1; the presence of the electron-withdrawing group increased
TABLE 1: The aforementioned solids' specific area and acidity.

\begin{tabular}{lccc}
\hline Entry & Solid & Surface area $\left(\mathrm{m}^{2} / \mathrm{g}\right)$ & Acidity $\left(\mathrm{mmol} \mathrm{NH}_{3} / 100 \mathrm{~g}\right)$ \\
\hline 1 & B & 50 & 21.6 \\
2 & Ca-B & 48 & 21.1 \\
3 & H-B & 82 & 30.9 \\
4 & AlPB & 139 & 29.0 \\
5 & AlZrPV & 208 & 36.7 \\
6 & MO & 246 & 17.8 \\
\hline
\end{tabular}

the carbonyl's electrophilic nature and favoured the formation of the respective isoquinoline in this aldehyde [10]. 3-hydroxy-4-methoxybenzaldehyde (vanillin) 2; the presence of electron-donating groups in this aldehyde reduced the carbonyl's electrophilic nature and led to isoquinoline having low yields. The following were used as catalysts: acetic acid, a natural bentonite from Colombia (B) which has been extensively characterised in previous work [19], homoionised calcium bentonite $\mathbf{B}$ with $0.5 \mathrm{M}$ calcium chloride (Ca-B), Al-pillared bentonite B (AlPB) [19], bentonite $\mathbf{B}$ activated with chlorhydric acid $\left(\mathrm{H}^{+}\right.$-bentonite) (H-B) [20], a mixed oxide $\left(\mathrm{Al}_{2} \mathrm{O}_{3}-\mathrm{MgO}, \mathrm{M}^{3+} /\left(\mathrm{M}^{2+}+\mathrm{M}^{3+}\right)=\right.$ $0.5)$ (MO) [21], and an Al-Zr pillared vermiculite (10.5: 1.5) (AlZrPV) [22].

The textural properties of the solids being studied were characterised by their surface area, using the $\mathrm{N}_{2}$ physisorption technique at $77 \mathrm{~K}$, and acidity by $\mathrm{NH}_{3}$ temperature programmed desorption $\left(\mathrm{NH}_{3}-\mathrm{TPD}\right)[23,24]$.

The results presented in Table 1 show that natural clay and that homoionised with calcium (B and $\mathbf{C a}-\mathbf{B}$ ) (entries 1 and 2) had low surface areas and low acidity, such characteristics not being very promising for catalysing the Pictet-Spengler reaction. Pillared vermiculite (AlZrPV) (entry 5) had a large surface area and high acidity, meaning that it could be expected that it would be an efficient catalyst for the PictetSpengler reaction. The modified bentonites (H-B and AlPB) (entry 3 and 4) had mid-sized surface areas and high acidity, such conditions likewise being favourable for being used as a catalyst in this reaction. The mixed oxide (entry 6) had large surface area but low acidity; if acidity is a necessary condition for catalysing the Pictet-Spengler reaction, then this should lead to lower yields.

The Pictet-Spengler reaction was carried out using $100 \mathrm{mg}$ of dopamine hydrobromide in all cases and stoichiometric amounts of the respective aldehyde in methanol as solvent, and $100 \mathrm{mg}$ of each solid as catalyst (Scheme 2). Diluted solutions ( $35 \mathrm{~mL}$ methanol) were used to avoid disrupting equilibrium by the product becoming precipitated. 


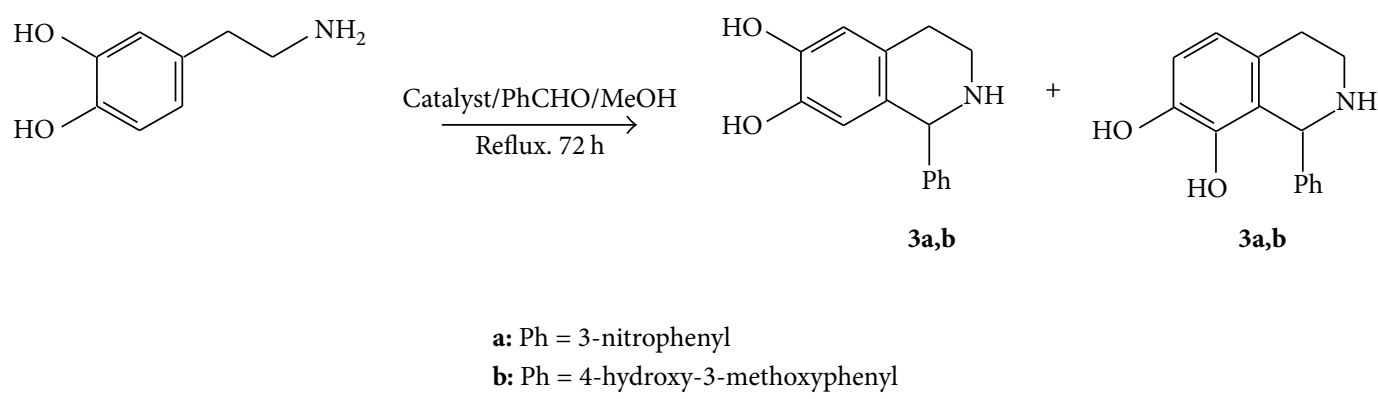

Scheme 2: Pictet-Spengler-type reaction involving dopamine hydrobromide and aldehydes.

TABLE 2: Pictet-Spengler reaction between dopamine hydrobromide and aldehydes $\mathbf{1}$ and 2.

\begin{tabular}{|c|c|c|c|c|}
\hline Entry & Aldehyde & Catalyst & Yield conversion $(\%)^{\mathrm{a}}$ & $3 / 4$ \\
\hline 1 & 1 & Acetic acid & 46 & $97 / 3$ \\
\hline 2 & 1 & B & 87 & $82 / 18$ \\
\hline 3 & 1 & Ca-B & 69 & $88 / 12$ \\
\hline 4 & 1 & H-B & 32 & $100 / 0$ \\
\hline 5 & 1 & AlPB & 82 & $100 / 0$ \\
\hline 6 & 1 & AlZrPV & 63 & $94 / 6$ \\
\hline 7 & 1 & MO & 100 & $86 / 14$ \\
\hline 8 & 2 & B & 52 & $65 / 35$ \\
\hline 9 & 2 & Ca-B & 81 & $93 / 7$ \\
\hline 10 & 2 & H-B & 40 & $67 / 33$ \\
\hline 11 & 2 & AlPB & 69 & $97 / 3$ \\
\hline 12 & 2 & AlZrPV & 35 & $65 / 35$ \\
\hline 13 & 2 & MO & 84 & $83 / 17$ \\
\hline
\end{tabular}

Combined ${ }^{1} \mathrm{H}$-NMR of $\mathbf{3}$ and $\mathbf{4}$.

The reactions were carried out in reflux conditions for 72 hours to ensure the greatest possible conversion with each catalyser being studied; this time was greater than reported for an acetic-acid-catalysed reaction.

Table 2 shows that all the catalysts used led to the respective isoquinoline with both aldehydes studied. Large differences were observed regarding the reaction's yield and regioselectivity.

Contrary to what had been expected, the best yields were obtained when the mixed oxide was used as catalyst (Table 2, entries 7 and 13). The strong electrophilic nature of 3nitrobenzaldehyde 1 led to complete conversion to isoquinoline; complete conversion was not obtained for vanillin 2 (84\%) but its yield was much superior to that obtained when acetic acid was used as catalyst [10]. A possible explanation for such pattern was that mixed oxide exhibited acid-base pairs due to the presence of $\mathrm{M}^{2+}-\mathrm{O}^{2-}$ sites; these acid sites activated a Schiff base intermediate due to the formation of an iminium cation and favoured nucleophilic addition. The basic sites interacted with dopamine phenol hydroxyls thereby increasing the ring's nucleophilic nature and favouring the aromatic electrophilic substitution reaction. Such activation of the ring likewise occurred for dopamine carbon 3 and carbon 5 , leading to regioselectivity becoming reduced regarding that observed for the acetic-acid-catalysed reaction.

It is worth pointing out that aluminium pillared bentonite (AlPB) (Table 2, entries 5 and 11) led to good yields and total regioselectivity with the aldehydes being studied. The good yields from the reaction with this solid could have been associated with the starting bentonite's increased acidity following pillarisation and improved textural properties facilitating access to the modified clay's acid sites by molecules from the reaction. Its good yield and total regioselectivity make this solid a good candidate for further studies directed towards the synthesis of more complex isoquinoline alkaloids.

Bentonite homoionised with calcium chloride (Ca-B) (Table 2, entries 3 and 9) also led to an interesting pattern. The reaction with aldehyde having electrodonor groups 2 produced high yield and total regioselectivity whilst that with aldehyde having electroattracting groups $\mathbf{1}$ had low yield and poor regioselectivity. Such pattern was consistent with previous studies which have proposed that calcium ions are attractive Lewis acids having many applications in organic synthesis and showing that their efficiency depends on the aldehyde's structural characteristics [14].

Pillared vermiculite (AlZrPV) (Table 2, entries 6 and 12) and chlorhydric-acid-activated bentonite (H-B) (Table 2 , 
entries 4 and 10) had poor reaction yields in spite of having the greatest acidity. These two solids did not seem to be appropriate for catalysing the Pictet-Spengler reaction and the results showed that greater acidity did not necessarily lead to better yields. Natural bentonite (B) from Colombia led to greater yield than that obtained with acetic acid but its regioselectivity was poor (Table 2 , entries 2 and 8 ), possibly due to the material's deficient textural properties thereby affecting the conformations which reagents could take within the catalyst, thus impeding the product of interest being obtained.

The results presented in Table 2 were obtained using dopamine hydrobromide as starting reagent; the respective isoquinoline hydrobromide was obtained as product in all cases. The great differences in yield and regioselectivity observed led to supposing that hydrobromic acid did not present important catalytic effects in the reaction conditions used here. Dopamine (freebase) was made to react with aldehyde $\mathbf{1}$ using mixed oxide (MO) as catalyser and 12-hour reflux to reject possible catalytic effects caused by hydrobromide dopamine and establish whether 72 hours' reflux was really necessary. The expected product was obtained in such reaction conditions ( $95 \%$ yield); this result confirmed that the hydrobromide group had no catalytic effects and that 12 hours' reflux was sufficient for the reaction to occur with high yield. NMR spectrum analysis revealed the presence of regioisomer $\mathbf{3} \mathbf{a}$ as the sole product.

\section{Conclusion}

This work thus used solids having different surface areas and acidity as an alternative for isoquinoline synthesis by means of the Pictet-Spengler reaction. Using a mixed oxide led to the best yields and good selectivity, whilst the reaction catalysed by a pillared bentonite led to good yields and total selectivity. The results revealed no direct relationship between the catalyst's acidity and the reaction's yield.

\section{Acknowledgments}

The authors wish to acknowledge the Universidad Nacional de Colombia for financing this work (DIB research project no. 14178).

\section{References}

[1] J. D. Scott and R. M. Williams, "Chemistry and biology of the tetrahydroisoquinoline antitumor antibiotics," Chemical Reviews, vol. 102, no. 5, pp. 1669-1730, 2002.

[2] D. L. Minor, S. D. Wyrick, P. S. Charifson, V. J. Watts, D. E. Nichols, and R. B. Mailman, "Synthesis and molecular modeling of 1-phenyl-1,2,3,4-tetrahydroisoquinolines and related 5,6,8,9tetrahydro-13bH-dibenzo[a,h]quinolizines as D1 dopamine antagonists," Journal of Medicinal Chemistry, vol. 37, no. 25, pp. 4317-4328, 1994.

[3] R. Naito, Y. Yonetoku, Y. Okamoto, A. Toyoshima, K. Ikeda, and M. Takeuchi, "Synthesis and antimuscarinic properties of quinuclidin-3-yl 1,2,3,4-tetrahydroisoquinoline-2-carboxylate derivatives as novel muscarinic receptor antagonists," Journal of Medicinal Chemistry, vol. 48, no. 21, pp. 6597-6606, 2005.

[4] R. Quevedo, L. Núñez, and B. Moreno, "A rare head-head binding pattern in bisbenzylisoquinoline alkaloids," Natural Product Research, vol. 25, no. 9, pp. 934-938, 2011.

[5] R. Quevedo, E. Baquero, and M. Quiñones, "1-Phenylisoquinoline larvicidal activity against culex quinquefasciatus," Natural Product Research, vol. 26, no. 12, pp. 1094-1100, 2012.

[6] E. D. Cox and J. M. Cook, "The Pictet-Spengler condensation: a new direction for an old reaction," Chemical Reviews, vol. 95, no. 6, pp. 1797-1842, 1995.

[7] R. Quevedo and B. Moreno-Murillo, "One-step synthesis of a new heterocyclophane family," Tetrahedron Letters, vol. 50, no. 8, pp. 936-938, 2009.

[8] N. Nuñez-Dallos, A. Reyes, and R. Quevedo, "Hydrogen bond assisted synthesis of azacyclophanes from l-tyrosine derivatives," Tetrahedron Letters, vol. 53, no. 5, pp. 530-534, 2012.

[9] S. D. Cho, S. Y. Song, E. J. Hur et al., "Regioselectivity of PictetSpengler cyclization: synthesis of halotetrahydroisoquinolines," Tetrahedron Letters, vol. 42, no. 36, pp. 6251-6253, 2001.

[10] R. Quevedo, E. Baquero, and M. Rodriguez, "Regioselectivity in isoquinoline alkaloid synthesis," Tetrahedron Letters, vol. 51, no. 13, pp. 1774-1778, 2010.

[11] B. Saha, S. Sharma, D. Sawant, and B. Kundu, "Application of the Pictet-Spengler reaction to aryl amine substrates linked to deactivated aromatic heterosystems," Tetrahedron, vol. 64, no. 37, pp. 8676-8684, 2008.

[12] A. Saito, J. Numaguchi, and Y. Hanzawa, "Pictet-Spengler reactions catalyzed by Brønsted acid-surfactant-combined catalyst in water or aqueous media," Tetrahedron Letters, vol. 48, no. 5, pp. 835-839, 2007.

[13] T. Pesnot, M. C. Gershater, J. M. Ward, and H. C. Hailes, "Phosphate mediated biomimetic synthesis of tetrahydroisoquinoline alkaloids," Chemical Communications, vol. 47, no. 11, pp. 3242-3244, 2011.

[14] M. J. Vanden Eynden and J. P. Stambuli, "Calcium-catalyzed pictet-spengler reactions," Organic Letters, vol. 10, no. 22, pp. 5289-5291, 2008.

[15] K. Manabe, D. Nobutou, and S. Kobayashi, "Catalytic PictetSpengler reactions using $\mathrm{Yb}(\mathrm{OTf})_{3}$," Bioorganic \& Medicinal Chemistry, vol. 13, no. 17, pp. 5154-5158, 2005.

[16] R. Sheldon, I. Arends, and U. Hanefeld, In Green Chemistry and Catalysis, Wiley-VCH, Weinheim, Germany, 2007.

[17] Y. F. Wang, Z. B. Song, C. X. Chen, and J. S. Peng, "PictetSpengler condensation reactions catalyzed by a recyclable $\mathrm{H}^{+}$montmorillonite as a heterogeneous brønsted acid," Science China Chemistry, vol. 53, no. 3, pp. 562-568, 2010.

[18] A. Hegedüs and Z. Hell, "One-step preparation of 1-substituted tetrahydroisoquinolines via the Pictet-Spengler reaction using zeolite catalysts," Tetrahedron Letters, vol. 45, no. 46, pp. 8553-8555, 2004.

[19] J. G. Carriazo, M. A. Centeno, J. A. Odriozola, S. Moreno, and R. Molina, "Effect of Fe and Ce on Al-pillared bentonite and their performance in catalytic oxidation reactions," Applied Catalysis A, vol. 317, no. 1, pp. 120-128, 2007.

[20] M. Molina and S. Moreno, "Hidroconversión de heptano sobre una bentonita colombiana y una saponita española pilarizadas con aluminio y activadas con ácido," Revista Colombiana de Química, vol. 30, no. 2, pp. 133-146, 2001.

[21] D. A. Aguilera, A. Perez, R. Molina, and S. Moreno, "Cu-Mn and Co-Mn catalysts synthesized from hydrotalcites and their 
use in the oxidation of VOCs," Applied Catalysis B, vol. 104, no. 1-2, pp. 144-150, 2011.

[22] A. Campos, B. Gagea, S. Moreno, P. Jacobs, and R. Molina, "Decane hydroconversion with Al-Zr, Al-Hf, Al-Ce-pillared vermiculites," Applied Catalysis A, vol. 345, no. 1, pp. 112-118, 2008.

[23] N. R. Sanabria, M. A. Centeno, R. Molina, and S. Moreno, "Pillared clays with Al-Fe and Al-Ce-Fe in concentrated medium: synthesis and catalytic activity," Applied Catalysis A, vol. 356, no. 2, pp. 243-249, 2009.

[24] L. Chmielarz, P. Kuśtrowski, M. Zbroja, B. Gil-Knap, J. Datka, and R. Dziembaj, "SCR of $\mathrm{NO}$ by $\mathrm{NH}_{3}$ on alumina or titania pillared montmorillonite modified with $\mathrm{Cu}$ or $\mathrm{Co}$ : part II. Temperature programmed studies," Applied Catalysis B, vol. 53, no. 1, pp. 47-61, 2004. 

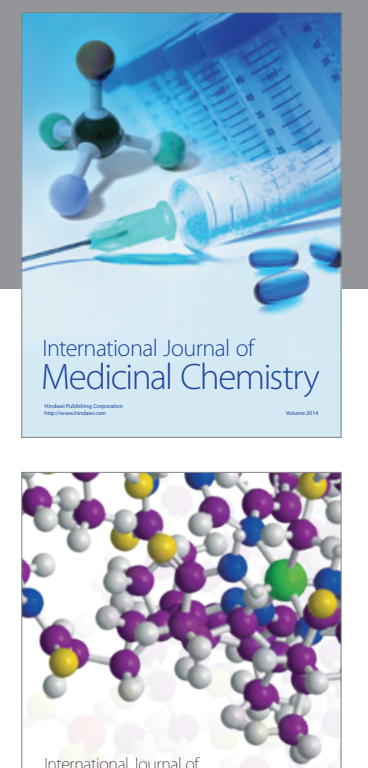

\section{Carbohydrate} Chemistry

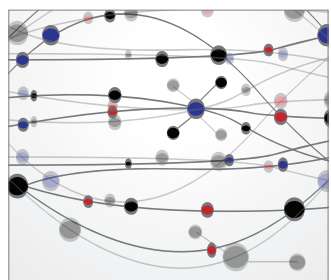

The Scientific World Journal
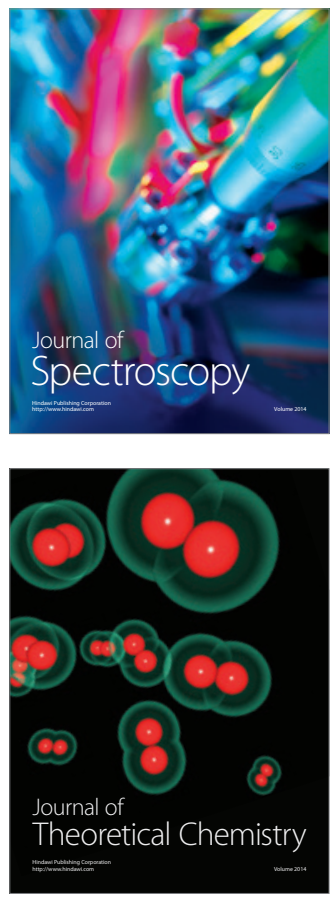
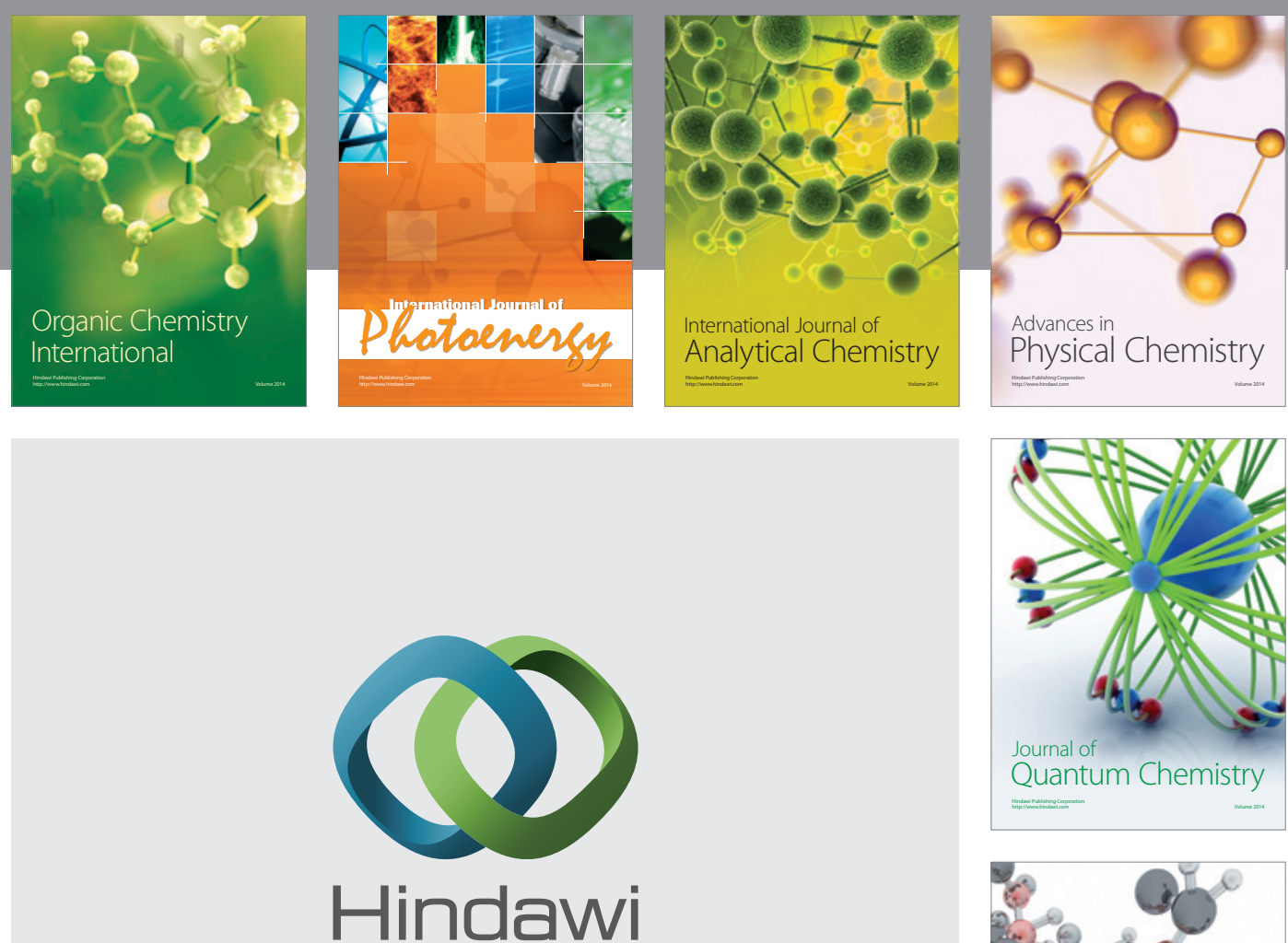

Submit your manuscripts at

http://www.hindawi.com

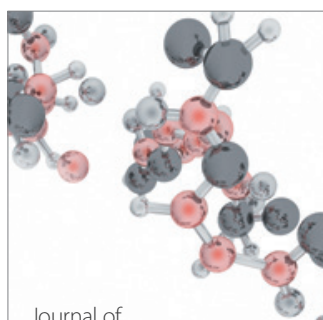

Analytical Methods

in Chemistry

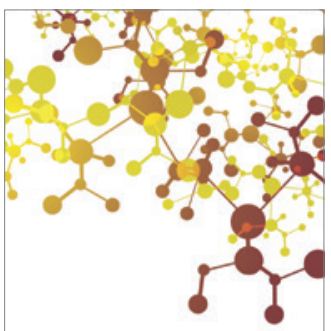

Journal of

Applied Chemistry

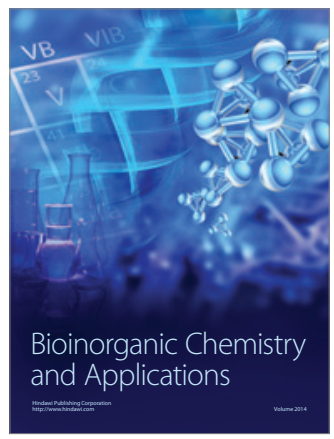

Inorganic Chemistry
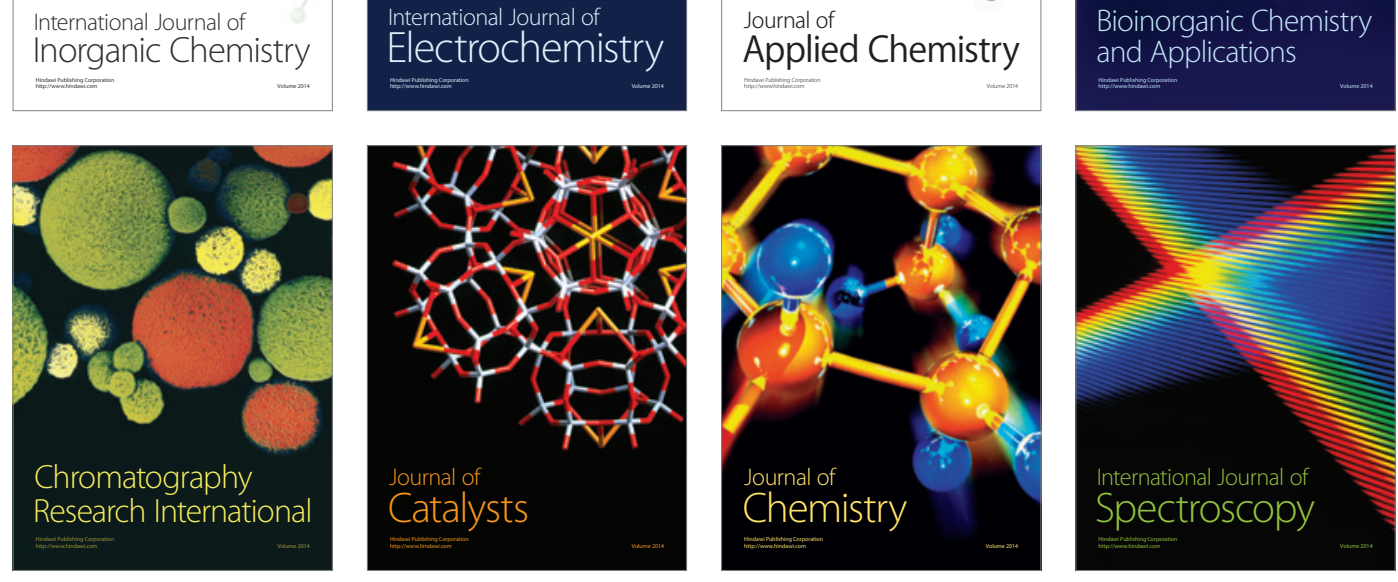